\title{
LACTULOSE VERSUS LACTITOL IN ACUTE HEPATIC ENCEPHALOPATHY (HE).
}

1. MBBS, FCPS (Gastro) Consultant Gasteroentologist Madinah Hospital Faisalabad.

2. MBBS, FCPS (Medicine) Assistant Professor of Medicine Madinah Teaching Hospital, University of Faisalabad, Faisalabad.

3. MBBS, FCPS (Medicine)

Assistant Professor Department of Medicine Mayo Hospital Lahore.

4. MBBS, FCPS (Medicine) Assistant Professor of Medicine KEMU, Mayo Hospital Lahore.

5. MBBS, FCPS Medicine Consultant Physician of Medicine Madinah Hospital Faisalabad.

6. FCPS Medicine PGR

Mayo Hospital Lahore.

7. MBBS, PGPN (USA) Medical Officer Pediatric Medicine Government General Hospital, Faisalabad.

Correspondence Address: Dr. Muhammad Ahsan House No. 8A, Tec Town, Satyana Road, Faisalabad. salman_azhar2010@yahoo.com

Article received on:

15/10/2019

Accepted for publication:

$25 / 12 / 2019$

\section{INTRODUCTION}

The end result of hepatocellular injury resulting in fibrosis and nodular regeneration of liver is called Cirrhosis. ${ }^{1}$ Cirrhotic liver is becoming more and more prevalent in our country due to the increasing incidence of Hepatitis $\mathrm{C}^{2}{ }^{2}$

Prevalence of cirrhosis in Pakistan is 234,112 people. ${ }^{3}$ Hepatic encephalopathy (HE) affects up to $80 \%$ of the cirrhotic patients. ${ }^{4} \mathrm{HE}$ is a condition associated with disordered central nervous system function resulting from failure of the liver to detoxify noxious agents of gut origin because of hepatocellular dysfunction and portosystemic shunting. ${ }^{1}$
Shahid Rasool ${ }^{1}$, Salman Azhar ${ }^{2}$, Talha Munir ${ }^{3}$, Mian Sajjad Ahmad ${ }^{4}$, Muhammad Saeed Akhtar ${ }^{5}$, Rizwan Abbas ${ }^{6}$, Muhammad Ahsan

RACT... Hepatic encephalopathy (HE), a syndrome observed in some patients with effects and better tolerated. However, literature showed equal efficacy of both drugs. So we (East, West, North, South), Mayo Hospital, Lahore. Period: 6 Months June 2017 to Dec 2017 Material \& Methods: 570 patients were included through non-probability, consecutive sampling after informed consent. Initial grade of $\mathrm{HE}$ was assessed and patients were randomly divided in two groups by using lottery method i.e. lactulose or lactitol. Patients were admitted to ward for management and kept under observation for 5 days. After 5 days, HE grades was measured again, then improvement in grade of HE (effectiveness) was measured. All data was entered and analyzed by using SPSS version 21.0. Chi-square was applied to compare both groups effectiveness taking p-value $\leq 0.05$ as significant. Results: In this study the mean age of the was $44.22 \pm 11.81$ years, the male to female ratio of the patients was $2.4: 1$. The mean were from lactitol group and the difference was significant $(p<0.0 .5)$. Conclusion: Our udy results concluded that Lactitol is better choice for the treatment of patients with acute Key words: $\quad$ Cirrhosis, Hepatic Encephalopathy, Lactulose, Lactitol.

Article Citation: Rasool S, Azhar S, Munir T, Ahmad MS, Akhtar S, Abbas R, Ahsan M. Lactulose versus lactitol in acute hepatic encephalopathy (HE). Professional Med J 2020; 27(8):1595-1601. DOI: 10.29309/TPMJ/2020.27.08.4245

Pathogenesis of HE in cirrhosis is complex, however there is a consensus that ammonia is a key toxin in $\mathrm{HE}$, which may sensitize the brain to different precipitating factors. ${ }^{5,6}$

The most utilized non-absorbable disaccharide for HE is Lactulose.(1:4, B-galactosido-fructose) Lactulose, a synthetic disaccharide, is comprised of the monosaccharide lactose and galactose, and is available as syrup. Doses are generally titrated with typical doses of $20 \mathrm{~g} / 30 \mathrm{~mL}$ orally three to four times per day to achieve two to four semi-soft stools daily. A second non-absorbable disaccharide has also been used in the treatment of $\mathrm{HE}$ which is lactitol (B-galactosido-sorbitol), It is a disaccharide analog of lactulose which is 
extensively metabolized by colonic bacteria in the small intestine. But neither absorbed nor broken down. It is accessible in a profoundly dissolvable crystalline powder Form. Clinical preliminaries have detailed lactitol to be an effective in treatment of HE with dosage of 10-12 g every 6 hours, titrated to two bowel movements daily. ${ }^{7}$

Lactitol has fewer side effects in the treatment of $\mathrm{HE}$ compared to lactulose. It is better tolerated and more palatable because of its more pleasant taste, moreover cathartic effect is more predictable. $^{8}$

In a study lactitol was considered more palatable. ${ }^{9}$ While Heredia et al. reported that thorough clinical resolution of $\mathrm{HE}$ occurred in 5 (25\%) patients given lactulose and in $6(30 \%)$ cases given lactitol. These outcomes demonstrate that in the administration of $\mathrm{HE}$ lactitol is as compelling as lactulose. ${ }^{10}$

Another examination revealed that good reaction to treatment was gotten for 19 (86\%) patients getting lactitol and in 14 (78\%) of those accepting lactose. ${ }^{11}$

Basis of this study is to compare the viability of lactulose $\mathrm{v} / \mathrm{s}$ lactitol for acute hepatic encephalopathy among patients. It has been observed in literature that lactitol and lactulose, both have equal effectiveness in terms of resolution of symptoms, but one study had showed that lactitol has more benefits as compared to lactulose. There is no local study available, so we have designed this study to see that which is the most effective drug for resolution of $\mathrm{HE}$ in cirrhotic patients and also to resolve the disparity as observed in literature.

\section{MATERIAL \& METHODS}

After the approval of synopsis from the hospital ethical review committee a randomized clinical trial was conducted for 6 months at Department of Medicine, Mayo Hospital, Lahore. size of the sample was 570 (285 patients per group) was calculated with $80 \%$ power of test, $5 \%$ level of significance and expected percentage of effectiveness i.e. $86 \%$ with lactitol and $78 \%$ with lactulose in HE patients.

570 cirrhotic patients (cirrhosis for $>6$ months) of 15-65 years age of both genders with clinical diagnosis of hepatic encephalopathy and with history of drowsiness were incorporated through non-probability, consecutive sampling and written assent was taken. Patients with neuropsychiatric problems due to causes other than hepatic cirrhosis (on medical record) like uremic encephalopathy (eGFR $<30 \mathrm{ml} / \mathrm{min} / 1.73 \mathrm{~m}^{2}$ and ultrasonography showing echogenic kidneys), septicemia (TLC $<4000$ or $>11,000 /$ ul, hypo or hyperthermia, tachycardia, tachypnea) and those with other systemic problems like diabetes and cardiac problems (abnormal ECG) on previous medical record were excluded. Patients were labeled having cirrhosis when coarse echo texture of liver is seen on ultrasound abdomen for at least 6 months.

Acute hepatic encephalopathy was defined when these cirrhotic patients presented with a compliant of drowsiness $<24$ hours (GCS < 8/15) with West Haven criteria score $\geq 1$ grade. After accessing the initial grade of HE, patients were randomly isolated in two gatherings by utilizing lottery technique i.e. lactulose $(30 \mathrm{ml} /$ day) or lactitol (12 g/day) for treatment.

Demographic data like name, age, gender and address was noted. Patients were admitted in the ward for management of $\mathrm{HE}$ as per protocol. One group was given lactulose and the other group lactilol and was kept under observation for 5 days for improvement of symptoms and grade of HE. Effectiveness was measured after 5 days of start of initial treatment by using West Haven criteria ${ }^{12}$ i.e. improvement in grade of the patient was labeled as effectiveness.

Data collected on predesigned proforma was closely handled SPSS 20. Numerical variables like age was represented as mean $\pm S D$ and categorical variable like gender and effectiveness was expressed as frequency and percentages. Chi-square was applied to compare both groups taking $p$-value $\leq 0.05$ as significant. Data was characterized for age, gender, grade of $\mathrm{HE}$, 
duration of cirrhosis to deal with effect modifiers. Post-stratification chi-square test was applied. P-value $\leq 0.05$ was considered as significant.

\section{RESULTS}

570 cases were enrolled in this present study. $44.22 \pm 11.81$ years was the mean age of the patients with least and most extreme ages of 25 and 6 years respectively. Table-I

\begin{tabular}{|c|c|c|}
\hline \multirow{4}{*}{ Age (years) } & N & 570 \\
\cline { 2 - 3 } & Mean & 44.22 \\
\cline { 2 - 3 } & SD & 11.81 \\
\cline { 2 - 3 } & Minimum & 25 \\
\cline { 2 - 3 } & Maximum & 65 \\
\hline
\end{tabular}

Table-I. Descriptive statistics of age (years).

In this study female patients were $28.95 \%$ and $71.05 \%$ patients were males. The male to female proportion of the patients was $2.4: 1$.

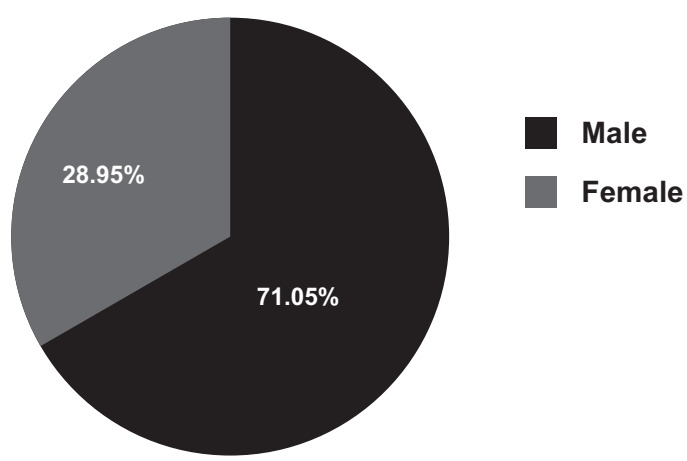

Figure-1. Frequency distribution of gender.

\begin{tabular}{|l|c|c|}
\hline \multirow{2}{*}{\begin{tabular}{|l|} 
Duration of \\
cirrhosis
\end{tabular}} & $\mathrm{n}$ & 570 \\
\cline { 2 - 3 } & Mean & 3.73 \\
\cline { 2 - 3 } & Minimum & 1.61 \\
\cline { 2 - 3 } & Maximum & 1.00 \\
\hline \multicolumn{2}{|c|}{ Table-II. Descriptive statistics of duration of cirrhosis } \\
(months).
\end{tabular}

The study results showed that before treatment HE two grade was found in $232(40.7 \%)$ patients, three grade was found in $168(29.5 \%)$ patients and grade four was found in $170(29.8 \%)$ patients. Table-III

\begin{tabular}{|l|c|c|c|}
\hline \multicolumn{2}{|c|}{} & Frequency & Percent \\
\hline \multirow{3}{*}{$\begin{array}{l}\text { HE Grade } \\
\text { before }\end{array}$} & Two & 232 & 40.7 \\
\cline { 2 - 4 } treatment & Three & 168 & 29.5 \\
\cline { 2 - 4 } & Four & 170 & 29.8 \\
\cline { 2 - 4 } & Total & 570 & 100.0 \\
\hline
\end{tabular}

Table-III. Frequency distribution of HE grade before treatment.

In our study zero grade after treatment was noticed in $213(37.4 \%)$ patients, one grade was noticed in $133(23.3 \%)$ patients, two grade was found in $143(25.1 \%)$ patients, three was noticed in $57(10 \%)$ patients and four was seen in $24(4.2 \%)$ patients. Table-IV

\begin{tabular}{|l|c|c|c|}
\hline \multicolumn{2}{|c|}{} & Frequency & Percent \\
\hline \multirow{4}{*}{$\begin{array}{l}\text { HE Grade } \\
\text { after }\end{array}$} & Zero & 213 & 37.4 \\
\cline { 2 - 4 } treatment & One & 133 & 23.3 \\
\cline { 2 - 4 } & Two & 143 & 25.1 \\
\cline { 2 - 4 } & Three & 57 & 10.0 \\
\cline { 2 - 4 } & Four & 24 & 4.2 \\
\cline { 2 - 4 } & Total & 570 & 100.0 \\
\hline
\end{tabular}

Table-IV. Frequency distribution of HE grade after treatment.

In this examination the general effectiveness was accomplished in $94.39 \%$ patients and it was not accomplished in $5.61 \%$ patients.

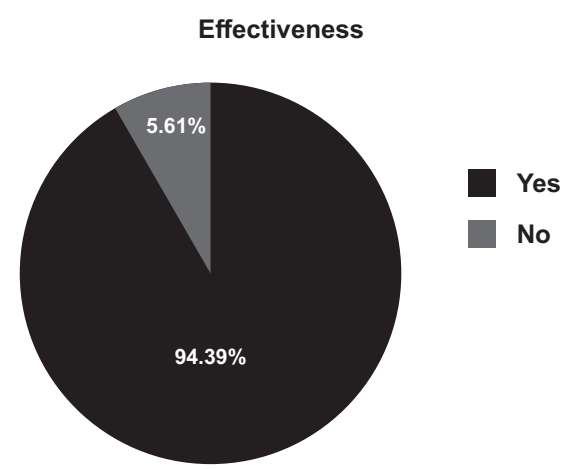

Figure-2. Frequency distribution of effectiveness.

The study results demonstrated that effectiveness was accomplished in 538 cases, 263 cases of lactulose group and 275 of lactitol group, comparably the adequacy was not accomplished in 32 cases, 22 from lactulose group and 10 of lactitol group. There is noteworthy distinction 
found statistically between the study groups and effectiveness of the patients. i.e $p$-value $=0.029$. Table-V

\begin{tabular}{|l|c|c|c|c|c|}
\hline \multicolumn{2}{|c|}{} & \multicolumn{2}{c|}{ Study Group } & Total & P-Value \\
\cline { 3 - 6 } & & Lactu-lose & Lactitol & & \\
\hline \multirow{2}{*}{$\begin{array}{l}\text { Effective- } \\
\text { ness }\end{array}$} & Yes & 263 & 275 & 538 & \\
\cline { 2 - 5 } & No & 22 & 10 & 32 & \multirow{2}{*}{0.029} \\
\hline \multicolumn{2}{|c|}{ Total } & 285 & 285 & 570 & \\
\hline
\end{tabular}

Table-V. Comparison of effectiveness in both study groups.

Chi value $=4.77, p$-value $=0.029$ (Significant) .

\begin{tabular}{|c|c|c|c|c|c|c|}
\hline & \multicolumn{2}{|c|}{ Study Group } & \multirow[b]{2}{*}{ Total } & \multirow{2}{*}{$\begin{array}{c}\text { P- } \\
\text { Value }\end{array}$} \\
\hline & & & $\begin{array}{l}\text { Lactu- } \\
\text { lose }\end{array}$ & Lactitol & & \\
\hline \multirow{4}{*}{$\begin{array}{c}\text { Effective- } \\
\text { ness }\end{array}$} & \multirow{2}{*}{ Male } & Yes & 190 & 193 & 383 & \multirow{2}{*}{0.201} \\
\hline & & No & 14 & 8 & 22 & \\
\hline & \multirow{2}{*}{ Female } & Yes & 73 & 82 & 155 & \multirow{2}{*}{0.044} \\
\hline & & No & 8 & 2 & 10 & \\
\hline
\end{tabular}

Table-VI. Comparison of effectiveness in both study groups stratified by gender.

In this study among male patients the viability was acheived in 383 cases, 190 of them were lactulose group and 193 of lactitol group, while in female patients the effectiveness was accomplished in 155 cases, 73 cases were of lactulose group and 82 were of lactitol group. Noteworthy distinction was found statistically between the investigation groups and effectiveness in female patients. i.e $\mathrm{p}$-value $=0.044$ Table-VI.

In our study in below 4 months cirrhosis duration the effectiveness was achieved in 356 cases, 184 of them were of lactulose group and 172 of lactitol group, comparably in over 4 months cirrhosis term patients the viability was accomplished in 79 cases, 103 cases from lactulose group and 82 of lactitol group. Factually huge contrast was found between the examination groups and effectiveness in below 4 months cirrhosis duration patients. i.e p-value $=0.05$ Table-VII.

In the study of patients with HE grade before treatment, the effectiveness in grade two $\mathrm{HE}$ patients was accomplished in 231 cases, 117 cases from lactulose group while 114 from lactitol group, In 161 cases the effectiveness in grade three HE was found, similarly the effectiveness in grade four HE patients was accomplished in 146 cases, 61 cases of lactulose group and 85 of lactitol group. There is noteworthy contrast found between the study groups and effectiveness in before treatment $\mathrm{HE}$ grade four patients. i.e $\mathrm{p}$-value $=0.008$ Table-VIII.

The study results demonstrated that in patients with $\mathrm{HE}$ grade after treatment, the effectiveness in grade two HE patients was accomplished in 142 cases, 61 cases of lactulose group and 81 of lactitol group, similarly the effectiveness in grade three HE patients was accomplished in 50 cases, 18 of lactulose group and 32 of lactitol group. There is no noteworthy contrast statistically found between the study groups and effectiveness in after treatment $\mathrm{HE}$ grades. i.e $\mathrm{p}$-value $=0.43 \& 0.411$ respectively Table-IX.

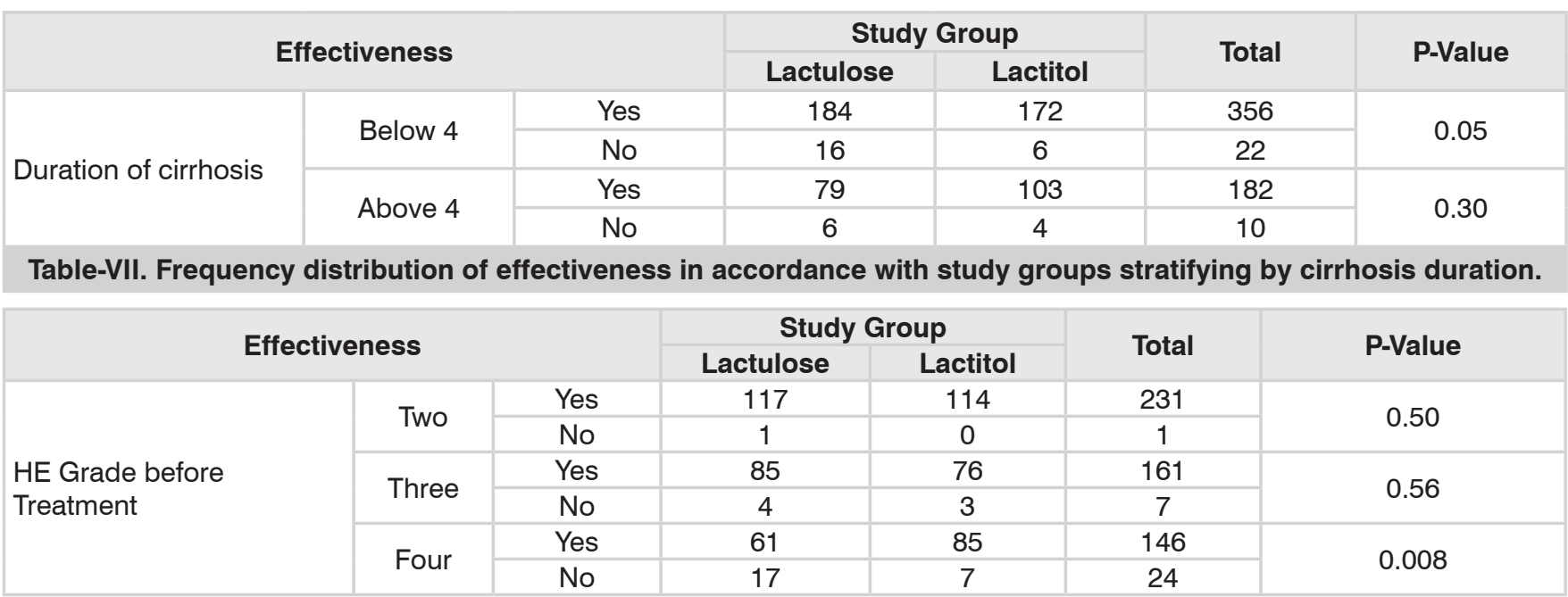




\begin{tabular}{|c|c|c|c|c|c|c|}
\hline \multirow{2}{*}{\multicolumn{3}{|c|}{ Effectiveness }} & \multicolumn{2}{|c|}{ Study Group } & \multirow{3}{*}{$\begin{array}{c}\text { Total } \\
142 \\
\end{array}$} & \multirow{2}{*}{ P-Value } \\
\hline & & & Lactulose & Lactitol & & \\
\hline \multirow{3}{*}{ HE Grade after treatment } & Two & Yes & 61 & 81 & & 0.43 \\
\hline & \multirow{2}{*}{ Three } & Yes & 18 & 32 & 50 & \multirow{2}{*}{0.411} \\
\hline & & No & 4 & 3 & 7 & \\
\hline
\end{tabular}

Table-IX. Frequency distribution of effectiveness in accordance with study groups stratifying by HE grade after treatment.

\section{DISCUSSION}

The trial was directed at Department of Medicine OPD and Emergency, Mayo Hospital, Lahore to look at the viability of lactulose $\mathrm{v} / \mathrm{s}$ lactitol in patients with acute hepatic encephalopathy.

One of the intricacies of liver cirrhosis is Hepatic encephalopathy $(\mathrm{HE})$. It has an extensive financial effect as it reduces the individual's personal life quality and it becomes a necessity for the patient to be admitted to the hospital for treatment regularly. For $\mathrm{HE}$, lactulose is the most generally used non-absorbable disaccharide.

In our study, overall efficacy was achieved in 538(94.39\%) patients in which 263 cases were from lactulose group and 275 were from lactitol group, likewise the efficacy was not possible in 32 cases, 22 were from lactulose group and 10 were from lactitol group. Measurably essential differentiation was found between the assessment groups and effectiveness of the patients. i.e $p$-value $=0.029$. Our result's demonstrated that lactitol is more efficacious as related to lactulose. A portion of the studies considered here are in support and while few are contrary of our findings.

Marsha $Y$ et al brought about their investigation that toward the conclusive part of the arrangement, The patients in the lactitol gathering about $67 \%$ and from lactulose gathering about $69 \%$ were clinically in good health. In any case, the patients that were administered with lactulose reacted altogether quite sluggishly than the patients that were administered with lactitol. ${ }^{9}$

A Study by Uribe $M$ et al demonstrated it showed that a great reaction to treatment was obtained from the patients receiving lactitol and lactose enemas ie $19(86 \%)$ patients treated with lactitol and 14 (78\%) patients treated with lactose. They reasoned that acidifying agents like lactose and lactitol are compelling and better for the treatment of acute nitrogenous portal-systemic encephalopathy than faucet water enemas. ${ }^{11}$

53 patients with acute hepatic encephalopathy were enrolled in one study, for 5-10 days they were treated with lactitol $60 \mathrm{~g}$ each day, $\ln 81 \%$ of patients lactitol was found to be compelling.

Camma et al demonstrated in the investigation that encephalopathy treated by lactitol turned out to be as successful as various disaccharides: pooled chances proportion was 0.83, 95\% confidence interval was $0.38-1.82 .{ }^{13}$

Pai et al exhibited in their Study that lactitol and lactulose are successful in the treatment of PSE, though the effect of lactitol seems slightly superior to that of lactulose in our study. Lactitol is more acceptable to our patients due to better palatability and less side effects. Lactitol is another good alternative in the treatment of PSE. ${ }^{14}$

In 1992 Pierre Blanc portrayed that no quantifiable differentiation between helpful impacts of lactitol and lactulose, yet it demonstrates a higher repeat of flatulence with lactulose. This recommends lactitol ought to be required than lactulose for the treatment of chronic HE. ${ }^{15}$

On contrary the study directed by D. Heredia et al in 1987 demonstrated that no reactions owing to treatment were seen in either gathering. In the administration of patients with cirrhosis and acute PSE the outcomes demonstrate lactitol is as successful as lactulose. ${ }^{10}$

Dr. Oliviero Riggio et al deduced in their study that 
lactitol may be better endured and for the long haul aversion of Episodes of HE in cirrhotics with Portal-Systemic Shunt is as viable as lactulose. ${ }^{16}$

Heredia et al. reported that thorough clinical constancy of $\mathrm{HE}$ occurred in $5(25 \%)$ patients given lactulose and in $6(30 \%)$ cases given lactitol. In the association of HE outcomes exhibit that lactitol is as viable as lactulose. ${ }^{10}$

\section{CONCLUSION}

Our study results concluded that compared to lactulose the better decision for the treatment of patients with acute hepatic encephalopathy is Lactitol. More efficacy was achieved in lactitol group patients than in lactulose group patients. Now in future, we can implement the use of lactitol instead of lactulose for management of $\mathrm{HE}$.

Copyright@ 25 Dec, 2019.

\section{REFERENCES}

1. Friedman LS. Liver, biliary tract and pancreatic disorders. In: McPhee SJ, Papadakis MA, Rabow MW, Education $\mathrm{M}-\mathrm{H}$, editors. Current medical diagnosis \& treatment. USA: McGraw-Hill; 2012. p. 661-7.

2. Mumtaz K, Ahmed US, Abid S, Baig N, Hamid S, Jafri W. Precipitating factors and the outcome of hepatic encephalopathy in liver cirrhosis. $J$ College Physicians \& Surgeons. 2010; 20:514.

3. Murray CJ, Ezzati M, Flaxman AD, Lim S, Lozano R, Michaud C, et al. GBD 2010: Design, definitions, and metrics. The Lancet. 2013; 380:2063-6.

4. Montgomery JY, Bajaj JS. Advances in the evaluation and management of minimal hepatic encephalopathy. Current gastroenterology reports. 2011; 13:26-33.

5. Bismuth M, Funakoshi N, Cadranel J-F, Blanc P. Hepatic encephalopathy: From pathophysiology to therapeutic management. Euro $\mathrm{J}$ gastroenterology \& hepatology. 2011; 23:8-22.

6. Albrecht J, Zielińska M, Norenberg MD. Glutamine as a mediator of ammonia neurotoxicity: a critical appraisal. Biochemical pharmacology. 2010; 80:13038.
7. Sharma P, Sarin SK. Disaccharides in the treatment of hepatic encephalopathy. Hepatic Encephalopathy: Springer; 2012. p. 141-58.

8. Faruqui AA, Joshi C, Balakumar P, Mahadevan N, Kumar $\mathrm{R}$, Kumar MS, et al. Lactitol: A review of its use in the treatment of constipation. Int J Recent Adv Pharm Res. 2012; 2:1-5.

9. Morgan MY, Hawley KE. Lactitol vs. lactulose in the treatment of acute hepatic encephalopathy in cirrhotic patients: a double-blind, randomized trial. Hepatology. 1987; 7:1278-84.

10. Heredia D, Caballeria J, Arroyo V, Ravelli G, Rodes J. Lactitol versus lactulose in the treatment of acute portal systemic encephalopathy (PSE): A controlled trial. Journal of hepatology. 1987; 4:293-8.

11. Uribe M, Campollo O, Vargas F, Ravelli GP, Mundo F, Zapata L, et al. Acidifying enemas (lactitol and lactose) vs. nonacidifying enemas (tap water) to treat acute portal-systemic encephalopathy: A double-blind, randomized clinical trial. Hepatology. 1987; 7:639-43.

12. Wijdicks FM. Hepatic Encephalopathy. NEJM 2016; 375:1660-70.

13. Cammà $C$, Fiorello $F$, Tinè $F$, Marchesini $G$, Fabbri $A$, Pagliaro L. Lactitol in treatment of chronic hepatic encephalopathy. Digestive diseases and sciences. 1993; 38:916-22.

14. Pai C, Huang Y, Jeng W, Chan C, Lee S. Treatment of porto-systemic encephalopathy with lactitol verus lactulose: A randomized controlled study. Chinese medical journal; Free China ed. 1995; 55:31-6.

15. Blanc P, Daures JP, Rouillon JM, Peray P, Pierrugues R, Larrey D, et al. Lactitol or lactulose in the treatment of chronic hepatic encephalopathy: Results of a meta analysis. Hepatology. 1992; 15:222-8.

16. Riggio O, Balducci G, Ariosto F, Merli M, Pieche U, Pinto $G$, et al. Lactitol in prevention of recurrent episodes of hepatic encephalopathy in cirrhotic patients with portal-systemic shunt. Digestive diseases and sciences. 1989; 34:823-9. 


\begin{tabular}{|c|c|c|c|}
\hline \multicolumn{4}{|c|}{ AUTHORSHIP AND CONTRIBUTION DECLARATION } \\
\hline Sr. \# & Author(s) Full Name & Contribution to the paper & Author(s) Signature \\
\hline 1 & Shahid Rasool & Data analysis. & \\
\hline 2 & Salman Azhar & Data collection, Paper writing. & \\
\hline 3 & Talha Munir & Data collection, Paper writing. & \\
\hline 4 & Mian Sajjad Ahmad & Data collection, Paper writing. & \\
\hline 5 & M. Saeed Akhtar & Data collection, Paper writing. & \\
\hline 6 & Rizwan Abbas & Paper writing. & \\
\hline 7 & Muhammad Ahsan & Data entry, data analysis & \\
\hline
\end{tabular}

